Jurnal Pemberdayaan: Publikasi Hasil Pengabdian kepada Masyarakat

Vol. 4, No. 3, Desember 2020, Hal. 279-282

ISSN:2580-2569; e-ISSN:2656-0542

DOI: https://doi.org/10.12928/jp.v4i3.2838

\title{
Pemanfaatan Museum dalam Pelestarian Budaya Daerah Lampung Sebagai Upaya Pengembangan Media Pembelajaran Guru Sekolah Dasar
}

\author{
Maman Surahman, Sugiyanto, Rizky Drupadi, Deviyanti Pangestu \\ FKIP Universitas Lampung, Jl. Prof. Dr. Soemantri Brojonegoro No. 1 Bandar Lampung \\ Email: deviyanti.pangestu@fkip.unila.ac.id
}

\begin{abstract}
ABSTRAK
Kegiatan ini dilatarbelakangi oleh tuntutan perubahan paradigma guru dalam mengembangkan media pembelajaran sekolah dasar pada Kurikulum 2013 SD. Walaupun pemerintah telah menentukan KI dan KD untuk Kurukulum 2013 namun guru juga diharapkan mampu mengembangkan media pembelajaran untuk menunjang pembelajaran di kelas. Tujuan kegiatan ini untuk meningkatkan kompetensi pedagogik guru sekolah dasar di Kota Bandar Lampung dalam merancang media pembelajaran di SD sesuai dengan tuntutan Kurikulum 2013, dan juga agar guru di Bandar Lampung diharapkan mampu mengembangkan media pembelajaran yang mengimplementasikan pelestarian budaya daerah Lampung.
\end{abstract}

Kata kunci: Museum, Media Pembelajaran, Budaya Lampung

\section{ABSTRACT}

This activity is motivated by the demands of a paradigm shift in developing a media teacher teaching elementary school in 2013 Elementary School Curriculum. Although the government has determined KI and KD for Kurukulum 2013, teachers are also expected to be able to develop learning media to support learning in the classroom. The purpose of this activity is to improve the pedagogical competence of elementary school teachers in the city of Bandar Lampung in designing instructional media in elementary schools in accordance with the demands of the 2013 Curriculum, and also so that teachers in Bandar Lampung are expected to be able to develop learning media that implements the preservation of Lampung regional culture.

Keywords: Museums, Learning Media, Lampung Culture

\section{PENDAHULUAN}

Media pembelajaran merupakan salah satu faktor pendukung dalam proses pembelajaran. Media adalah segala sesuatu yang dapat digunakan untuk menyalurkan pesan dari komunikator (pengirim pesan) ke komunikan (penerima pesan) sehingga dapat merangsang pikiran, perasaan dan minat serta perhatian siswa sedemikian rupa sehingga proses belajar terjadi. Media pembelajaran terdiri dari beberapa jenis, diantaranya : media grafis, media audio, media proyeksi diam, media proyeksi gerak dan audio visual, multimedia dan benda. Multimedia merupakan salah satu jenis media pembelajaran yang mampu menggantikan hampir semua peranan media yang ada.

Materi yang akan digunakan dalam pembuatan media ini adalah museum sebagai sumber belajar bagi guru SD untuk mengembangkan dan membuat media pembelajaran, sehingga dapat membantu dan meningkatkan pelaksanaan pembelajaran di kelas. Pada mulanya museum berfungsi sebagai gudang barang tempat di mana disimpan benda-benda warisan budaya yang bernilai luhur dan dirasakan patut disimpan. Kemudian fungsinya meluas kefungsi pemeliharaan, pengawetan, penyajian atau pameran, dan akhirnya fungsi ini 
meluas lagi sampai kefungsi untuk pendidikan. Seperti membina dan mengembangkan ilmu pengetahuan, teknolog, dan seni dalam rangka peningkatan dan penghayatan nilai budaya dan kecerdasan kehidupan bangsa.

Pada upaya pembinaan kebudayaan, secara implisit terkandung pengertian tentang pelestarian, khususnya menyangkut nilai-nilai luhur budaya bangsa. Pembinaan kebudayaan pada umumnya dilaksanakan melalui pendidikan atau lebih khusus disampaikan melalui pembelajaran di sekolah sekolah dasar, menengah, tinggi dan lembaga formal lainnya seperti museum. Kebudayaan akan mengalami perkembangan terkait dengan dinamika masyarakat pendukungnya yang mampu memanfaatkan museum sebagai sumber pembelajaran kebudayaan. Pesan-pesan pem- belajaran tentang kebudayaan yang ada dalam museum dapat diterima oleh seluruh masyarakat, termasuk siswa atau guru SD. Pertanyaan yang muncul dalam pikiran kita adalah apa sumber belajar itu dan seperti apa museum yang berfungsi sebagai sumber belajar, serta bagaimana strategi yang digunakan untuk menjadikan museum sebagai sumber belajar. Oleh karena itu, tujuan dari kegiatan pengabdian ini adalah untuk meningkatkan wawasan Guru SD tentang pengembangan media pembelajaran kurikulum 2013 SD dan pembelajaran tematik berbasis budaya daerah Lampung, serta meningkatkan keterampilan Guru SD dalam mengorganisir materi pembelajaran tematik terpadu dengan museum Lampung sebagai sumber belajar, dan mendesain media pembelajaran tematik terpadu berbasis budaya daerah Lampung dengan museum Lampung sebagai sumber belajar.

\section{METODE}

Metode yang digunakan dalam kegiatan ini adalah ceramah, diskusi dan workshop. Ceramah digunakan untuk menyamakan persepsi dan memperluas wawasan guru berkenaan dengan pemahaman tentang pelestarian budaya Lampung dan peran penting guru SD dalam pelestarian buaya Lampung, sedangkan workshop digunakan untuk melatih guru dalam memanfaatkan sumber belajar Museum Lampung guna membuat media pembelajaran di Sekolah Dasar. Kegiatan ini di laksanakan pada tanggal 10-12 September 2020, serta melibatkan 30 guru Sekolah Dasar di Kota Bandar Lampung.

\section{HASIL, PEMBAHASAN, DAN DAMPAK}

Hasil kegiatan pengabdian pada masyarakat yang berkenaan dengan "Pemanfaatan Museum dalam Pelestarian Budaya Daerah Lampung sebagai Upaya Pengembangan Media Pembelajaran Guru Sekolah Dasar”, dapat digambarkan pada Tabel 1.

Tabel 1. Hasil kegiatan pengabdian kepada masyarakat

\begin{tabular}{|c|c|c|c|c|}
\hline \multirow{2}{*}{ No } & \multirow{2}{*}{ Komponen } & \multirow{2}{*}{ Aspek } & \multicolumn{2}{|c|}{$\begin{array}{c}\text { Tingkat } \\
\text { Penguasaan }\end{array}$} \\
\hline & & & Pretest & $\begin{array}{c}\text { Post } \\
\text { tes }\end{array}$ \\
\hline \multirow[t]{3}{*}{1} & \multirow[t]{3}{*}{ Konsep } & 1. Peran guru dalam pelestarian budaya & 11 & 66 \\
\hline & & 2. Pengembangan media pembelajaran & 10 & 64 \\
\hline & & $\begin{array}{l}\text { 3. Pemanfaatan Museum sebagai sumber } \\
\text { belajar }\end{array}$ & 6 & 60 \\
\hline \multirow[t]{2}{*}{2} & \multirow{2}{*}{$\begin{array}{l}\text { Penyusunan } \\
\text { Program }\end{array}$} & 1. Mengorganisir materi pembelajaran & 4 & 62 \\
\hline & & 2. Merumuskan desain media pembelajaran & 4 & 62 \\
\hline
\end{tabular}

Tabel 1. menggambarkan bahwa kegiatan pelatihan ini sudah memberikan kotribusi terhadap peningkatan kemampuan guru, tetapi belum sesuai dengan target. Hal ini nampak dari aspek kemampuan tentang peran guru dalam pelestarian budaya, rata-rata skor pretest 
hanya 11 dan setelah mengikuti kegitan pelatihan ini meningkat menjadi rata-rata 66. Kemampuan tentang Pengembangan media pembelajaran, rata-rata skor sebelum mengikuti kegiatan 10 kemudian setelah mengikuti kegiatan menjadi 64. Rata-rata skor kemampuan tentang pemanfaatan museum sebagai sumber belajar sebelum kegiatan 6, setelah kegiatan meningkat menjadi 60 , begitu juga untuk aspek organisasi materi pelajaran dan merumuskan desain media pembelajaran masing-masing dari skor rata-rata 4 menjadi 62.

Data di atas mengundang keprihatinan untuk menindaklanjuti kondisi ini secara lebih sungguh-sungguh, secara faktual peningkatan kemampuan mereka sangat signifikan yaitu tidak kurang dari 50 point tetapi karena kemampuan awalnya sangat rendah maka dengan peningkatan yang signifikan tersebut, mereka belum dapat dikatagorikan menguasai konsep dan mendesain rencana pembelajaran secara mahir, sehingga dibutuhkan pelatihan tentang cara membuat media pembelajaran seperti tampak pada Gambar 1.

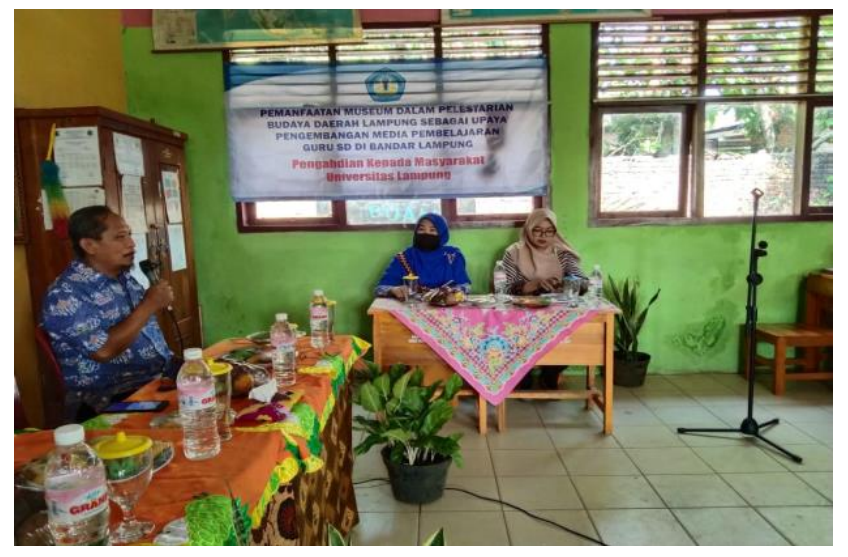

Gambar 1. Pemateri memberikan pelatihan cara membuat media pembelajaran

Pengembangan media pembelajaran dengan memanfaatkan Museum Lampung sebagai sumber belajar merupakan upaya dalam pelestarian dan pembentukan karakter pada siswa. Budaya Lampung yang mungkin semakin dilupakan generasi muda dipekenalkan melalui pendidikan, media pembelajaran juga disesuaikan dengan karakteristik siswa. Sehingga pembelajaran diharapkan memberikan dampak positif bagi pengalaman belajar siswa. Guru dan siswa akan diarahkan kepada pengalaman langsung yang dihadirkan melalui media pembelajaran, sebagaimana aktivitas yang dilakukan guru pada Gambar 2.

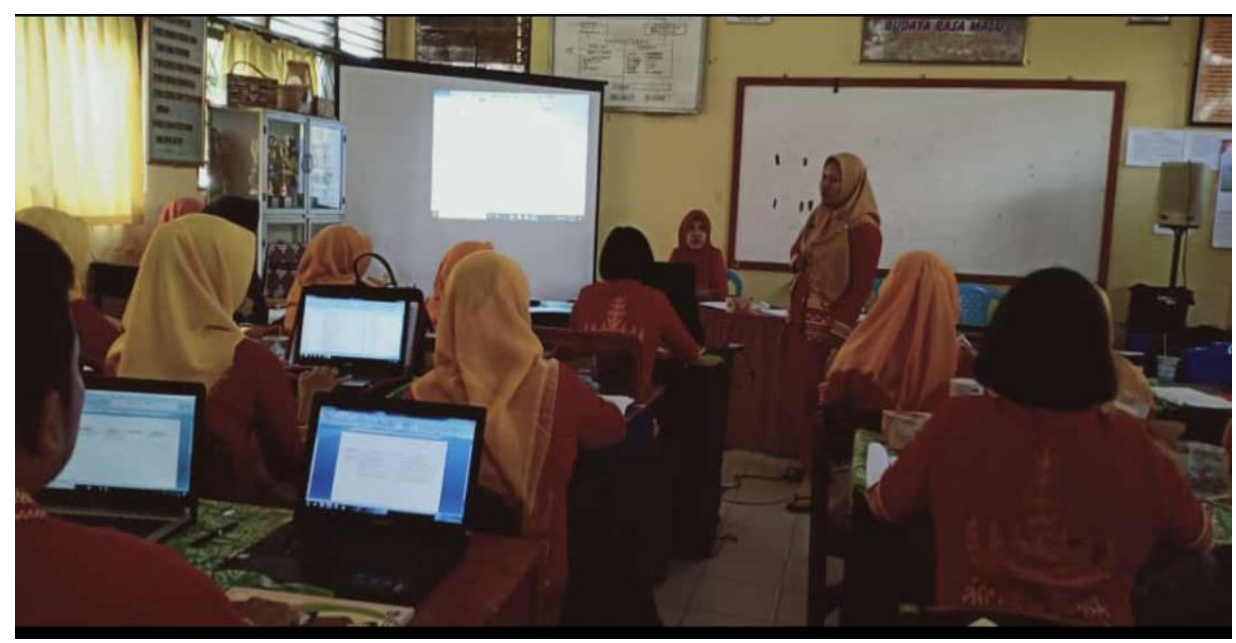

Gambar 2. Guru membuat media pembelajaran 
Kemampuan guru dalam mengembangkan media pembelajaran maupun merencanakan pembelajaran yang bermakna bagi siswa juga akan berkembang dan terus terasah. Pembelajaran menjadi tidak membosankan dan lebih menarik serta variatif. Pemanfaatan lingkungan sebagai pengalaman belajar siswa merupakan salah satu cara yang dapat dilakuakan guna mendukung ketercapaian tujuan pembelajaran.

Siswa diharapkan mampu menjaga dan melestarikan budaya mereka. Pemanfaatan museum sebagai sumber belajar juga membuat pengalaman belajar siswa menjadi terbentuk dengan sendirinya. Hal ini menjadikan pembalajran lebih bermakna dan berkesan bagi siswa, karena mereka mempelajari apa yang telah mereka ketahui dan lihat sendiri. Sehingga diharapkan guru mampu menggali kesempatan ini dengan sebaik-baiknya.

\section{SIMPULAN}

Hasil kegiatan pengabdian pada masyarakat menunjukkan bahwa terdapat peningkatan wawasan tentang pelestarian budaya Lampung dan media pembelajaran, serta terdapat peningkatan keterampilan guru SD dalam mengorganisir materi pelajaran, dan mendesain media pembelajaran.

\section{UCAPAN TERIMAKASIH}

Penulis mengucapkan terima kasih kepada seluruh pihak yang telah membantu pelaksanaan kegiatan pengabdian kepada masyarakat ini. Khusunya untuk LPPM Universitas Lampung yang telah memberikan dana penelitian, guru-guru dan mahasiswa yang ikut membantu lancarnya kegiatan ini.

\section{DAFTAR PUSTAKA}

Aristo, R. (2004). Media Pembelajaran. Jakarta: Direktorat Tenaga Kependidikan.

Arsyad, A. (2007). Media Pembelajaran. Jakarta: PT Raja Persada.

Hutchinson E. Sarah and Sawyer C. Stacey. (2000). Computers, Communications \& Information, McGraw Hill Companies Inc.

Jeffcoate Judith. (1995) Multimedia In Practice Technology and Applications, Prentice Hall International (UK) Limited.

Long Larry and Long Nancy. (2000). Computers $7^{\text {th }}$ Edition, Prentice-Hall Inc. 